\title{
The Importance of a Multidisciplinary Approach to High Voltage Electrical Injuries
}

\author{
Ho Hyoung Lee', Joong suck Kim², Min Koo Lee², Kyoung Hwan Kim², Sung Ho Han², \\ Soon Ho Chon ${ }^{3}$, Oh Sang Kwon ${ }^{2}$
}

${ }^{1}$ Department of Orthopedics, ${ }^{2}$ Department of Traumatology, ${ }^{3}$ Department of Thoracic Surgery, Regional trauma center, Cheju Halla General Hospital

The high voltage electrical injury is uncommon and is typically only reported in about 5 percent of major burn injuries. However, it is a major cause of amputation of extremities. Electrical burns are arbitrarily divided into high voltage (R1000 V) and low voltage $(\langle 1000 \mathrm{~V})$ injuries. In electrical injuries, decisions must be made about cardiac monitoring, emergent exploration and decompression of the extremity compartments, and the treatment for myoglobinuria. In this regard, we report of the importance of using a multidisciplinary approach to high voltage electrical injury.

Key Words: High voltage; Electrical injury; Multidisciplinary

(Trauma Image Proced 2018(1):17-19)

\section{CASE}

A 36-year-old female participated in paragliding during a visit to Jeju island. Due to a rogue wind gust, her and pilot crashed into a high voltage $(22000 \mathrm{~V})$ electrical wire. Her ankle was hung from the electrical wire. The pilot was in cardiac arrest upon arrival of emergency personnel at the scene. Her initial vital signs were $128 / 81 \mathrm{mmHg}-121 / \mathrm{min}-20 / \mathrm{min}-37.8^{\circ} \mathrm{C}$, and her EKG was nonspecific. She complained of severe pain in her left-side extremities. We found a severe burn (grade III-IV) on her left upper and lower extremities (Fig. 1.). We inserted a right subclavian central catheter and an additional internal jugular hemo-catheter for vigorous hydration and preparation of hemodialysis. Traumatologists performed an escharotomy on her upper and lower extremities and called for an orthopedic surgeon. The traumatologist and orthopedic doctor elected to perform an emergency operation (fasciotomy of the left upper limb and above-knee amputation of the left lower limb). Her initial urine myoglobulin level was $1923 \mathrm{mcg} / \mathrm{L}$.

After resuscitation, she was sent to the operation room. One orthopedic doctor and two traumatologists performed an above-knee amputation and fasciotomy, simultaneously (Fig. 2.).

For pain control and facilitation of further operational procedures, we kept the patient ventilated and under continuous infusion of sedatives and analgesics. After the first operation, we consulted a nephrologist and applied renal replacement therapy to her. We debrided and irrigated the necrotic tissue. Finally, she was transferred to the burn center for advanced burn management.

Received: November 3, 2017 Revised: May 14, 2018 Accepted: May 14, 2018

Correspondence to: Oh Sang Kwon, Department Traumatology, Cheju Halla General Hospital, 65, Doryeong-ro, Jeju-si, Jeju-do, Korea Tel: 82-64-740-5000, Fax: 82-64-743-3100, E-mail: dr73bear@hanmail.net

Copyright (c) 2018 Korean Association for Research, Procedures and Education on Trauma. All rights reserved.

@This is an open-access article distributed under the terms of the Creative Commons Attribution Non-Commercial License (http://creativecommons.org/ licenses/by-nc/4.0) which permits unrestricted noncommercial use, distribution, and reproduction in any medium, provided the original work is properly cited 


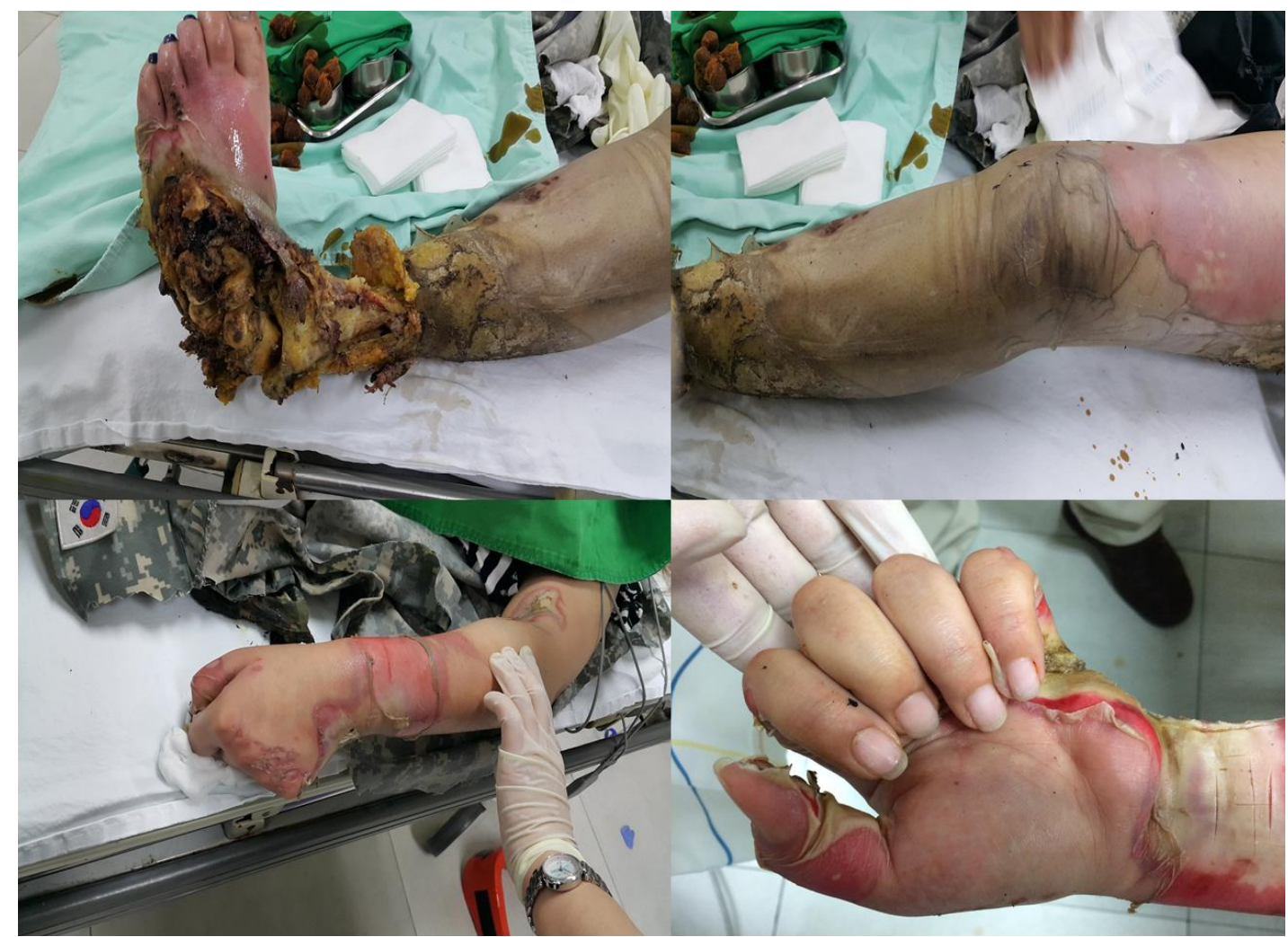

Fig. 1. Multiple extensive burn wounds are shown on the upper and lower extremities.

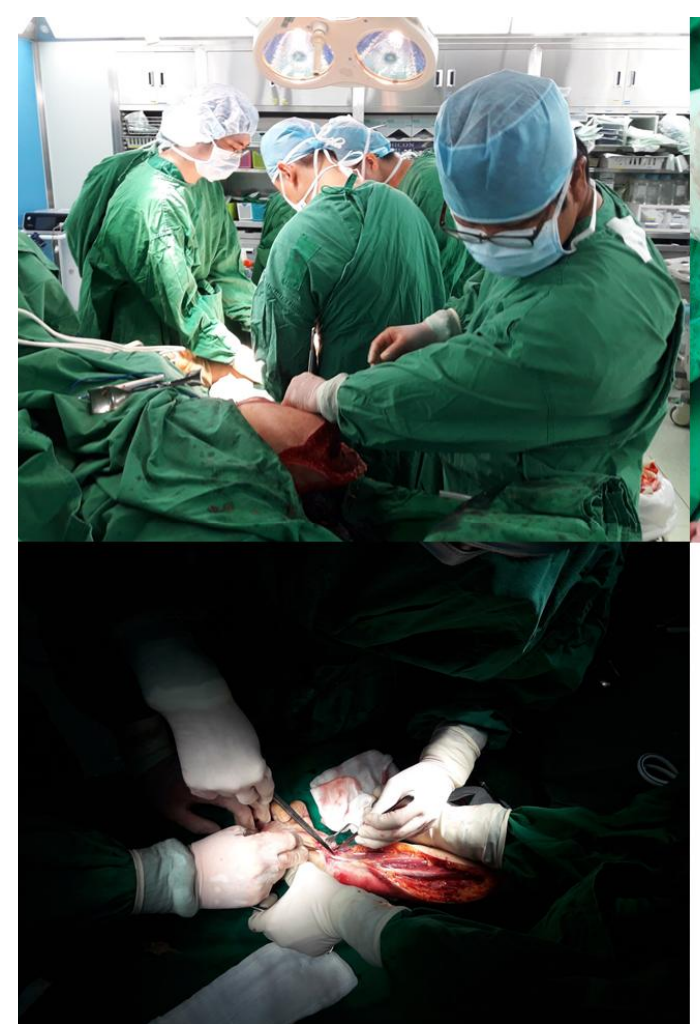

Fig. 2. Simultaneous above-knee amputation and fasciotomy 


\section{DISCUSSION}

In a high voltage electrical injury, after an initial resuscitation, decisions must be made regarding cardiac monitoring, emergent exploration and decompression of the extremity compartments, and treatment of myoglobinuria (1). It is important to cooperate with a multidisciplinary team to improve the patient's prognosis.

\section{Conflict of Interest Statement}

No potential conflict of interest relevant to this article was reported.

\section{REFERENCE}

1. O'Conor CE. Management of electrical injury in the emergency department. Irish medical journal. 2003;96(5):133-4. 